\title{
Transferência de tecnologia e desenvolvimento sustentável: o critt- ufjf e sua trajetória
}

\author{
Josane Gomes Weber Oliveira \\ Universidade Federal de Juiz de Fora \\ josane.weber@ufjf.edu.br \\ Albertina Dos Santos Souza \\ Universidade Federal de Juiz de Fora \\ albertina.souza@ufjf.edu.br \\ Marcelo Garcez De Oliveira \\ Universidade Federal de Juiz Fora \\ marcelo.garcez@engenharia.ufjfbr \\ Geovane Silva Xavier \\ niversidade Federal de Juiz de Fora \\ Geovane.xavier@engenharia.ufjf.br
}

\section{RESUMO}

Termos como desenvolvimento sustentável e desenvolvimento local e regional vem sendo cada vez mais associados a outros como inovação, transferência de tecnologia e empreendedorismo. Os Núcleos de Transferência de Tecnologia- NITs presentes nas Universidades Federais tem contribuído sobremaneira para que essa associação saia da teoria e passe à prática. $\mathrm{O}$ presente trabalho pretende apresentar a trajetória do Centro Regional de Inovação e Transferência de Tecnologia - CRITT da Universidade de Juiz de Fora e seu papel, até o momento, no desenvolvimento local e regional por meio de seus rocessos finalísticos bem como sugerir possíveis ações que permitam uma maior interação da Universidade com a comunidade em seu entorno. Utilizou-se a pesquisa documental de forma a levantar as realizações do Centro, relacionando-as com o levantamento das teorias sobre o assunto além de outras experiências já relatadas em artigos científicos. Evidenciase o quanto um organismo como o CRITT pode e deve contribuir para o desenvolvimento regional sustentável, sendo mais uma importante contrapartida que as IFEs oferecem à sociedade.

Palavras chave: inovação, transferência de tecnologia, desenvolvimento sustentável local e regional 


\section{INTRODUÇÃO}

Conforme Agustinho e Garcia (2018) as universidades são grandes celeiros de conhecimento onde se encontram várias expertises e linhas de pesquisa que resultam, muitas vezes, em produtos, processos e tecnologias inovadoras. Atualmente, a chamada triple helix tornou-se uma hélice quíntupla abrangendo universidade-empresa-governo, sociedade e levando em conta o ambiente natural. (MINEIRO ET ALL, 2019)

Os Núcleos de Inovação e Transferência de Tecnologia - NITs, existentes em algumas universidades, são espaços importantes que realizam a aproximação e interação entre os componentes dessa hélice, de forma que a tecnologia e o conhecimento deixem as bibliotecas e repositórios acadêmicos e possam fomentar a inovação e o empreendedorismo, além de promoverem o desenvolvimento sustentável. Assim, promovem o desenvolvimento socioeconômico sustentável na medida em que, difundindo conhecimento e aproximando as expertises tecnológicas dos empresários e empreendedores, podem agir como incentivadores na criação de novos empreendimentos, redutores da mortalidade precoce de empresas, auxiliares na manutenção e desenvolvimento de empresas já existentes e, ainda, com sua contribuição para criação e preparação de novos produtos e serviços. (AGUSTINHO E GARCIA, 2018)

O Centro Regional de Inovação e Transferência de Tecnologia - CRITT é o NIT da Universidade Federal de Juiz de Fora desde o advento da Lei de Inovação de 2004, embora já estivesse funcionando como Centro Regional de Inovação e Transferência de Tecnologia, desde abril de 1995.

O presente artigo teve como objetivo elencar os trabalhos realizados, até o momento, pelo CRITT-UFJF por meio de dois de seus processos finalísticos, a saber: Núcleo de empreendedorismo (Incubadora de Base Tecnológica, Condomínio de Empresas) e Núcleo de Transferência de Tecnologia - NTT e analisar sua participação como colaborador no desenvolvimento sustentável local e regional.

\section{Fundamentação Teórica}

Para subsidiar as análises realizadas nesse artigo serão abordados os seguintes assuntos: desenvolvimento local/regional, inovação e transferência de tecnologia. 


\subsection{Seção Secundária Da Fundamentação Teórica}

Autores como Sachs (2004) e De Britoo (2011) conceituam desenvolvimento sustentável como sendo um processo de mudança dos meios e da estrutura de produção de forma que promovam a geração de distribuição igualitária.

Para Paulista, Varvakis e Montibeller-Filho (2008) e Pearce (1988) embora não haja consenso, a proposição mais aceita de desenvolvimento sustentável reúne o equilíbrio entre o bem-estar social e os vetores de desenvolvimento, de forma propiciar uma utilização ótima de recursos econômicos de cunho societal visando manter tais benefícios no futuro.

A Figura 1 traz a perspectiva de desenvolvimento regional nos diferentes eixos bem como suas interconexões. Assim, pode-se conseguir o desenvolvimento econômico com aumento da equidade social levando em conta as questões de ordem ambiental.

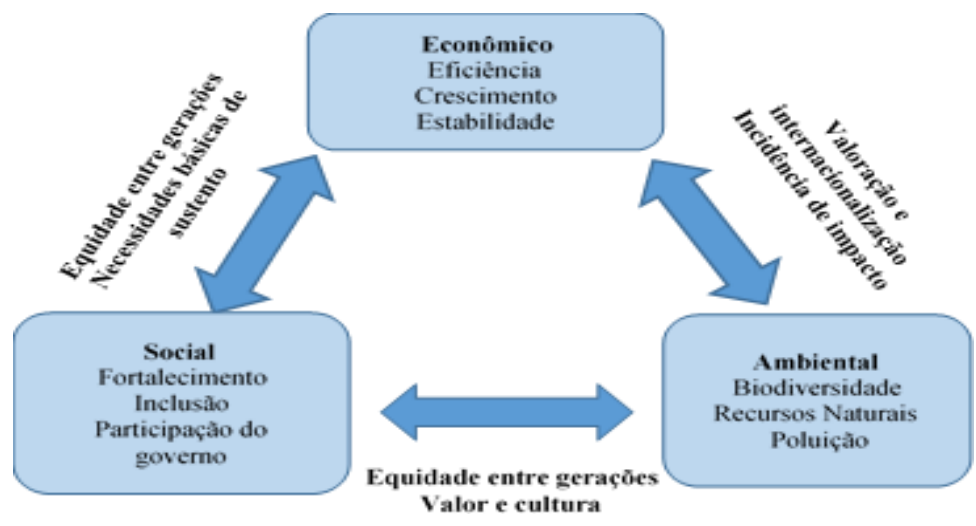

Figura 1: Elementos chaves do desenvolvimento sustentável e interconexões. Fonte: Alves Filho, 2003.

Do ponto de vista local, Milani (2005) entende que o desenvolvimento pressupõe uma transformação da realidade local que leve em consideração os aspectos prioritários da comunidade, o que exige uma preocupação consciente com a melhora efetiva da realidade agora e, também, no futuro.

De acordo com Buarque (1999) o desenvolvimento local implica em articular diferentes atores bem como esferas de poder, envolvendo a sociedade civil, as organizações não governamentais, instituições privadas e de ensino além do próprio governo local. Importante observar, que no caso do desenvolvimento local importa levar em conta os aspectos locais que possuem real significado em determinado território, considerando questões relativas à dinâmica demográfica e empresarial, comercial, bem-estar da população e preservação patrimonial, por exemplo. Assim, aspectos como mão de obra especializada, locais ambientalmente aprazíveis, condições tecnológicas facilitadoras e 
acessibilidade, quando alavancados podem ser benéficos, quando se pensa em desenvolvimento sustentável envolvendo os três aspectos.

Diversos são os estudos acadêmicos sobre a influência do grau de competitividade, seja de uma empresa ou um país, no seu processo de desenvolvimento. (SCHUMPETER,1985; PORTER,1991)

Conforme o Relatório The Global Competitiveness Report 2017-2018 que avaliou a competitividade em 137 países, o Brasil ocupa a 80a posição, tendo melhorado sua performance. Dentre os itens avaliados se encontra a capacidade de inovação e esse foi o pilar onde o país demonstrou maior progresso. O relatório apontou para uma maior capacidade de inovação, mais cooperação ente empresas, maior qualidade na pesquisa e cientistas e engenheiros melhor capacitados.

\subsection{Inovação}

Existem inúmeros conceitos para inovação e dentre eles pode-se citar o contido no Manual de Oslo. Inovação é:

[...] a implementação de um produto (bem ou serviço) novo ou significativamente melhorado, ou um novo processo, ou um novo método de marketing, ou um método organizacional nas práticas de negócios, na organização do local de trabalho ou nas relações externas. (OCDE; FINEP, 2005, p.55)

Pode-se classificar os modelos de inovação como sendo inovação aberta ou fechada.

Conforme Chesbrough (2003), o modelo de inovação aberta considera a interação existente entre academia, empresa e consumidores em um processo dinâmico de cocriação. Já o modelo de inovação fechada limita o processo inovador aos conhecimentos e tecnologias criados dentro das organizações, sem a participação de outras organizações externas.

O modelo de inovação aberta tem sido cada vez mais considerado e, autores como Etzkowitz e Leydesdorff (1995) entenderam que a dinâmica da inovação tecnológica seria efetivamente realizada por meio da interrelação entre as universidades, a indústria e os governos. A esse modelo denominaram hélice tripla.

A recentes mudanças no cenário global, no entanto, vêm agregando novos atores a essa dinâmica, uma vez que aspectos como desenvolvimento sustentável sócio econômico e ambiental vem sendo introduzidos nas agendas e ganhando destaque no cenário mundial. Conforme indicam Mineiro et al (2019 p. 78): 
No entanto, as recentes mudanças no cenário global expandiram a forma de relacionamento entre estes atores. A tradicional tríade formada por universidade-indústria- governo vem se fortalecendo com novos modelos de geração do conhecimento, incluindo a sociedade (Hélice Quádrupla - HQ) e o ambiente (Hélice Quíntupla) com hélices importantes na dinâmica da inovação.

O modelo da Hélice Quádrupla insere agentes como a sociedade civil, mídia e cultura de forma que se faz necessária uma ampla concepção da aplicação da inovação e da produção do conhecimento. Esse modelo considera a sociedade civil como usuária da inovação e impulsionadora de seus processos.

A hélice quíntupla, por sua vez, leva em consideração os ambientes naturais da sociedade como contexto para as outras abordagens. Dessa forma, o meio ambiente é considerado fator preponderante na sobrevivência e preservação da humanidade. (CARAYANNIS; RAKHMATULLIN, 2014; YOON; YANG; PARK, 2017)

De acordo com Mineiro et al (2019, p. 89)

A Quarta Hélice destaca as características da sociedade. No estudo, ela é definida de forma geral, como sociedade civil e comunidade ampla. Nesta hélice, os usuários têm participação direta no modelo, apoiando no desenvolvimento de inovações, há claramente um ambiente de cooperação, que nos remete a exemplos de inovação aberta.

A Quinta Hélice destaca problemas como o aquecimento global e a crescente preocupação com questões sustentáveis para o modelo. Ela remete a sustentabilidade como fator principal para o desenvolvimento regional. Os agentes representantes da hélice ainda são escassos, sendo que os estudos abordam teoricamente o meio ambiente, e atores relacionados a aspectos sócio ecológicos, vale destacar também a não associação a um ator. O papel desses atores é fomentar o desenvolvimento sustentável.

Assim, o modelo da Hélice Quíntupla está voltado para o equilíbrio sustentável entre o desenvolvimento social e o econômico, ou seja, transforma conhecimento científico e tecnológico em riqueza socioeconômica, utilizando para tanto as vocações locais.

Conforme Oliveira (2005, p.30-31)

Fica clara, então, a noção de desenvolvimento local/regional sustentável como uma forma de desenvolvimento de um determinado local ou região, que transcende a esfera econômica e inclui aspectos como o social, o 
cultural, o ecológico, o territorial e o político, sendo concebido de forma coletiva, na qual os vários atores sociais (mercado, Estado e sociedade civil) interagem de forma responsável.

Conforme (PETITINGA, 2006) atualmente é quase unânime o entendimento de que o desenvolvimento sustentável se dá por meio da interrelação entre fatores econômicos, sociais e ambientais. Para Macedo e Cândido (2011, p.4) “A questão econômica implica em melhores condições de trabalho - aumento de renda e riqueza - e esse fator gera melhorias na vida social, sendo que a problemática ambiental não pode ser dissociada desse processo." A partir das definições apresentadas, pode-se depreender que os habitats de inovação, os mecanismos de transferência de tecnologia e a interação entre diferentes atores econômicos, governamentais e científicos tecnológicos, com ênfase especial para as universidades, podem contribuir para o desenvolvimento sustentável local, regional e nacional.

\subsection{Transferencia De Tecnologia, Habitats de Inovação e Desenvolvimento Local}

A Tecnologia é o elemento essencial para o desenvolvimento econômico e social de um país e as Instituições Federais de Ensino - IFEs são capazes de impulsionar o mercado, de forma a garantir satisfação das necessidades ao transferir para as empresas o resultado de suas pesquisas de forma que, o termo tecnologia

[...] é usado pelos economistas para designar o conjunto de conhecimentos aplicados pelo homem para atingir determinados fins de natureza econômica, sendo que as inovações tecnológicas determinam, quase sempre uma elevação dos índices de produção industrial e um aumento da produtividade de trabalho (PIMENTEL, 1999, pag. 83).

Segundo o Manual de Transferência de Tecnologias Ecoeficientes (LODI, 2011):

Duas são as formas de se obter novas tecnologias. A primeira é por meio da pesquisa e desenvolvimento, produzida internamente na empresa ou em parceria com outras empresas, universidades e/ou centros de pesquisa. A segunda advém da comercialização de inovações, ou do que chamamos de "transferência de tecnologia". A transferência de tecnologia é o processo pelo qual conhecimentos, habilidades e soluções industriais são transferidos (por meio de um licenciamento) de uma empresa ou organização a outra. Esta transferência pode ampliar a capacidade de inovação da empresa 
"cliente", já que esta passa a ter contato com os novos conhecimentos, habilidades e soluções industriais licenciados.

A Lei 10973/2004, denominada Lei de Inovação, que dispõe sobre incentivos à inovação e à pesquisa científico e tecnológica no ambiente produtivo além de outras providências, em seu artigo 16, determina, em caráter obrigatório que as IFEs deverão dispor de Núcleo de Inovação Tecnológica próprio ou em associação com outras ICT, com a finalidade de gerir sua política de Inovação, sendo essa de fundamental importância para o processo de transferência de tecnologia nas Universidades.

Conforme Rosa (2014) os habitats de inovação como incubadoras e Parques Tecnológicos bem como os Núcleos de Inovação de Transferência de Tecnologia vêm ganhando cada vez mais importância como incentivadores e impulsionadores da inovação e empreendedorismo, além de contribuírem para o desenvolvimento sustentável nas regiões onde estão inseridos.

De acordo com Labiak (2012, p.19)

[...] as incubadoras se tornaram presentes em toda parte do mundo, onde os formuladores de políticas de desenvolvimento em nível nacional ou regional, começaram a perceber que este tipo de habitat é uma ferramenta de relevante importância no desenvolvimento econômico, social e inovador das regiões.

No tocante a transferência de tecnologias oriundas da pesquisa, do desenvolvimento de produtos/serviços e de conhecimento gerados em uma Universidade, para que possam atender de maneira eficiente os objetivos de desenvolvimento tecnológico, social e econômico, há um aporte de recursos financeiros feito pelos governos Federal, Estadual e Municipal com o intuito de capacitar e dotar de infraestrutura as IFEs para que atuem na pesquisa e desenvolvimento - P\&D. Isso se justifica uma vez que, por ser um processo demorado e de resultado incerto, a maioria das empresas preferem não investir em P\&D ou quando investem, o fazem em percentuais mínimos.

As IFEs utilizam-se do sistema de Propriedade Industrial, segundo Pimentel (1999), para influenciar o crescimento econômico, constituindo a referida propriedade um elemento de grande importância na competitividade empresarial e fazendo com que a atividade econômica flua de acordo com a qualidade de vida que proporciona. 
Para que a Transferência de Tecnologia se efetive, as Instituições Científicas e Tecnológicas celebram, por meio de instrumentos jurídicos denominados contratos, uma relação pelo qual uma parte se obriga a passar para outra uma tecnologia ou os conhecimentos técnicos oriundos desta, seja na forma de Propriedade Intelectual, na forma de "know how" ou Prestação de Serviços. (LOTUFO, 2009).

Uma grande aliada dos Núcleos de Inovação Tecnológica - NIT's, no que tange a transferência de tecnologia, é a Propriedade Intelectual cujo registro se adquire sob a forma de proteção das criações intelectuais desenvolvidas e

[...]se faz por meio das criações das Instituições e abrange as invenções e todas as formas de propriedade intelectual passíveis de proteção no Brasil (patentes, modelos de utilidade, desenhos industriais, programas de computador, topografia de circuitos integrados, novas cultivares ou cultivares essencialmente derivadas), bem como qualquer outro desenvolvimento tecnológico que possa surgir de um novo produto, processo ou aperfeiçoamento incremental. A inovação, por sua vez, requer que a criação seja implementada e disponibilizada na sociedade de forma bem sucedida (LOTUFO, 2009, pag.51).

Com a globalização o conhecimento e a transferência de tecnologia deixaram de ter fronteiras e para que a transferência seja realizada, para que o país saia bem sucedido com as transferências oriundas da Sociedade do Conhecimento, torna-se necessário que as pesquisas desenvolvidas pelas Universidades partam de um ambiente inovador, em constante transformações e atualizações para que se produza o que seja de interesse do mercado, a fim de que esse possa absorvê-lo e, só assim, se tornar um produto inovador. (LOTUFO, 2009).

Ainda segundo Lotufo (2009) a política de inovação no Brasil tem por objetivo primeiro reduzir o atraso social, econômico e tecnológico e isso passa por uma maior capacitação do pessoal técnico e científico. Para promover a capacitação nas IFEs foram criados órgãos governamentais tais como o Conselho Nacional de Pesquisas (CNPq), a Coordenação e Aperfeiçoamento de Pessoal de Nível Superior (CAPES) e a Financiadora de Estudos e Projetos (FINEP).

De acordo com Póvoa e Rapini (2010) o tema transferência de tecnologia universidade/indústria, apesar de sua relevância no tocante a sua influência no 
desenvolvimento econômico das nações, ainda é pouco estudado em países considerados em desenvolvimento.

Transferir Tecnologia não é uma atividade fácil. Tal dificuldade se dá por diversos motivos como falta de políticas institucionais e de pessoal qualificado, dificuldade de se estabelecer estratégias favoráveis de negociação, pessoal qualificado para preparação das proteções intelectuais, excesso de burocracias no serviço público, tempo gasto no trâmite público que envolve passagem pelas Procuradorias Federais, dificuldade de acompanhamentos de contratos de licenciamento de longa duração ou que envolvam diversas etapas de desenvolvimento, falta de conhecimento e inseguranças jurídicas, entre outros. Todavia, conforme Lotufo $(2009$, p.57) todos estes serviços podem ser "terceirizados e feitos com a ajuda de escritórios de patentes e consultores de inovação, porém respeitadas as políticas internas de cada instituição e de sua experiência na contratualização de convênios e contratos tecnológicos."

Conforme Santos e Sollero (2006) são inúmeras as dificuldades enfrentadas para se promover a inovação e a transferência de tecnologia entre universidade e empresa no Brasil. A legislação que rege o tema é recente e carece de mecanismos que uniformizem a operacionalização dos Núcleos de Inovação e Transferência de Tecnologia, há, ainda, o predomínio de interações com empresas de porte médio e grande, deixando micro e pequenas empresas desligadas dos benefícios oriundos da academia e a busca por especialistas e pesquisadores ainda passa por vias informais.

Também, pode-se citar o reduzido número de acordos de licenciamento bem como de transferência de know how.

Outro dificultador é de cunho cultural, uma vez que não há uma cultura empresarial em utilizar universidades como fontes de tecnologia (SANTANA E PORTO, 209).

A despeito das dificuldades, no entanto, a presença de habitats de novação e Núcleos de Inovação e Transferência de Tecnologia e proteção intelectual são mecanismos importantes na aceleração do desenvolvimento sustentável.

Arantes e Serpa (2012) entendem que o processo de inovação, unindo academia, empresas e governo impulsiona o desenvolvimento local e regional sob o amparo da economia do conhecimento. 


\section{Metodología}

A metodologia adotada no presente artigo é de cunho qualitativo uma vez que favorece uma melhor compreensão dos processos e dinâmicas que envolvem um fenômeno. Trata-se, também, de uma pesquisa de caráter exploratório, permitindo desenvolver hipóteses e problemáticas passíveis de investigações futuras (GIL, 1999) O método utilizado foi o estudo de caso com base em dados secundários, oriundos de pesquisa documental e a pesquisa bibliográfica, sendo a última utilizada como suporte para a análise dos dados.

Portanto, foram coletados dados referentes à produção realizada pelo CRITT, a partir do ano de1995 até os dias atuais.

A pesquisa bibliográfica utilizou bases de dados como Scielo, IBICT, CAPES e SPELL, sendo os artigos escolhidos por relevância e data de publicação.

A pesquisa documental foi realizada no site da Instituição bem como nos dados fornecidos pela direção do Centro.

\section{Resultados}

O Centro regional de Inovação e Transferência de Tecnologia - CRITT é um órgão da Universidade Federal de Juiz de Fora - UFJF cujo propósito é o de facilitar e realizar a transferência de tecnologia e fomentar o empreendedorismo bem como apontar soluções inovadoras de forma a contribuir para o aumento da competitividade do país. O Cento atua assessorando empreendedores e empresas no desenvolvimento de novos produtos/serviços ou no aperfeiçoamento dos processos de produção. Também atua na área de proteção do conhecimento.Desde sua criação no ano de 1995, o CRITT vem se consolidando como agente do desenvolvimento econômico regional, promovendo e estimulando o desenvolvimento social, o uso de tecnologias limpas e sustentáveis. (UFJF, 2019)

Possui três processos considerados finalísticos:

- A Incubadora de Base Tecnológica- apoia iniciativas empreendedoras por meio do suporte a novas empresas de base tecnológica, em especial nas áreas de gestão e infraestrutura, de forma que possam se preparar para os desafios do mercado até atingirem suficiente maturidade. Atualmente, além o processo próprio da incubação, a IBT tem se tornado um núcleo de incentivo ao empreendedorismo atuando com programas voltados para 
aqueles que tem apenas uma ideia e gostariam de saber como transformá-la em negócio.

- O Treinamento - consiste em realizar a transferência de tecnologia por meio de cursos, palestras, workshops e demais veículos de capacitação.

- Núcleo de Transferência de Tecnologia -que possui um setor voltado para a proteção do conhecimento e outro que realiza a ponte entre a academia e a indústria, viabilizando a transferência de tecnologia por meio de contratos e convênios de consultoria ou prestação de serviços.

O processo de Treinamento não será abordado nesse artigo uma vez que por motivos estruturais e de cunho institucional foi praticamente interrompido por alguns anos, se limitando a atividades de capacitação das empresas incubadas.

Além da incubadora, o CRITT também utiliza seu espaço como condomínio de empresas de base tecnológica, de forma a gerar sinergia entre as empresas condôminas e instituições de pesquisa e desenvolvimento, promovendo a cultura da inovação, aumentando a competitividade industrial e transferência de conhecimento e tecnologia. Com o estudo de viabilidade econômica já concluído, o Centro contará, também com um Parque Tecnológico que abrigará empresas, centros de pesquisa (privados e públicos), prestadores de serviço tecnológicos complexos e de apoio às atividades tecnológicas, atividades de pesquisa, desenvolvimento e inovação (CRITT, 2019).

E preciso mencionar que o governo do Estado de Minas Gerais lançou, em 2008, o Programa de incentivo à inovação- Pii, do qual o CRITT/ UFJF faz parte.

O programa é dividido em fases distintas: organização do trabalho e estudo inicial de viabilidade; estudos de viabilidade técnica, econômica e ambiental (EVTECIA); planejamento e desenvolvimento de produto e negócio (PDPN); e relação mercadológica. O PII transforma pesquisa em inovação tecnológica. O projeto foi desenvolvido baseado no cenário mineiro, organizando e integrando ações pontuais já existentes, proporcionando um suporte técnico completo até a eventual fase de inserção mercadológica dos projetos apoiados (CRITT, 2019). 
O CRITT se torna, então, um habitat de inovação com todas as condições de atuar como agente do desenvolvimento sustentável local e regional.

Ressalta-se, ainda, a participação da UFJF como membro da Câmara de Gestão, Educação e Política Ambiental do Conselho Municipal do Meio Ambiente - COMDEMA, juntamente com vários atores locais. O COMDEMA é um órgão deliberativo, responsável por propor diretrizes com relação ao desenvolvimento sustentável do município de Juiz de Fora. Trata-se de um Conselho cuja composição se divide de forma paritária entre a sociedade civil organizada e o poder público

A seguir, serão apresentados alguns dados sobre a atuação do CRITT nos últimos anos, de acordo com dois de seus processos finalísticos.

\section{- Incubadora De Base Tecnológica - Ibt}

Desde 1995, 30 (trinta) empresas incubadas na IBT-CRITT se graduaram, sendo que apenas duas estão com CNPJ suspenso. A média de idade das empresas graduadas que se encontram na ativa é de 17 (dezessete) anos. Isso pode indicar o quanto o auxílio e conhecimento adquirido no processo de incubação interferiu na saúde financeira e no desenvolvimento dessas empresas de base tecnológica. O desenvolvimento sustentável local/regional depende, também, de empresas que consigam se manter saudáveis e competitivas em um mercado altamente competitivo.

Além disso, esses empreendimentos continuam produzindo riqueza para a região, gerando postos de emprego e disseminando uma cultura de inovação, uma vez que se encontram sediadas na cidade de Juiz de Fora e se formaram segundo uma visão inovadora. Importante acrescentar que o trabalho do Centro não termina na graduação, mantendo sempre contato e portas abertas para que as empresas possam contar com os mecanismos de transferência de tecnologia e consultorias da UFJF.

Os dados levantados indicam, ainda, que 25 (vinte e cinco) empresas graduadas possuem CNPJ ativo, mas não apresentam evidência de atuação no mercado. Muitas empresas podem ter migrado para outras cidades e regiões ou até mesmo alterado sua razão social e, nesse caso, talvez seja interessante uma pesquisa mais acurada.

Ao todo, passaram pela IBT/CRITT 65 (sessenta e cinco) empreendimentos em 25 anos de atuação.

Atualmente se encontram incubadas quatro empresas de base tecnológica e fazem parte do Condomínio de Empresas outras três já graduadas. 
Os dados acima indicam diversas atividades que, inegavelmente, contribuem para o desenvolvimento local, seja por meio da divulgação de uma cultura de inovação, pelo incentivo à pesquisa universitária aplicada e a criação de novas empresas com condições de sobrevivência e crescimento no mercado local e regional.

As parcerias com órgãos governamentais e empresas como a EMBRAPA (MG) e SEBRAE (MG), por exemplo, além de projetos junto a órgãos de fomento como a FINEP e FAPEMIG mostram que a interação proposta por autores como Etzkowitz e Leydesdorff (1995) e Mineiro et al (2019) se faz presente.

$\mathrm{O}$ que anteriormente era apenas uma incubadora, atualmente ganhou um aspecto mais amplo tornando-se um Núcleo de Empreendedoriasmo.

\section{- Transferencia De Tecnologia - Patentes}

O Núcleo de Inovação e Transferência de Tecnologia - NIT do CRITT-UFJF compreende dois setores: Transferência de Tecnologia e Proteção do Conhecimento.

Os dados referentes aos projetos de transferência de tecnologia se referem aos anos de 2013 a 2019.

Ao todo foram 108 projetos, divididos conforme apresentado no Quadro 2.

QUADRO 1 - Número de Projetos de Transferência de Tecnologia CRITT/UFJF -

\section{3-2018}

\begin{tabular}{|l|l|}
\hline PROJETOS CONCLUÍDOS & Quantidade \\
\hline Cooperação técnica & 12 \\
\hline Prestação de serviço & 10 \\
\hline Pesquisa e Desenvolvimento - P\&D & 19 \\
\hline Pesquisa Compartilhada & 18 \\
\hline PROJETOS VIGENTES & \\
\hline Cooperação técnica & 23 \\
\hline Prestação de serviço & 06 \\
\hline Pesquisa e Desenvolvimento - P\&D & 24 \\
\hline Transferência de dados & 02 \\
\hline Termos de seção de equipamentos & 02 \\
\hline TOTAL & 108 \\
\hline
\end{tabular}

FONTE: elaborada pelos autores 
Os projetos vigentes consistem em parcerias envolvendo cerca de 20 (vinte) empresas, dentre elas Vale do Rio Doce, Petrobrás, Shell do brasil, RMSS Logística e grupo Bahamas, além de empresas locais como Instituto Oncológico, Innóvit (Encubada), LUPA e Imersa (incubada). Dentre os projetos já concluídos, houve a participação de mais 33 empresas e organizações diferentes das 20 já citadas, dentre elas o Instituto de Engenharia de Sistemas e Computadores, Tecnologia e Ciência da Universidade do Porto/Portugal, Votorantim do Brasil, KRON Instrumentos Elétricos, OPT (local), JM Localização e Logística (local), Ortofarma (local).

Conforme indicado por Santos e Sollero (2006) há um predomínio de interação com médias e grandes empresas, no entanto, percebe-se a ligação de empresas incubadas e graduadas e, ainda, que muitas das empresas de maior porte possuem algum tipo de filial ou representações locais.

Quanto às patentes, desde 1995, foram 118 (cento e dezoito) patentes depositadas sendo 3(três) já concedidas (Quadro 2). As invenções variam dentre as diferentes áreas do conhecimento química, tecnologia médica, produtos farmacêuticos, biotecnologia, engenharias e informática. Como exemplo, os inventos cujas patentes já foram concedidas são: MILKTEC - Equipamento para identificar adulteração no leite e similares, Arilhidrazonas - Agentes despigmentantes e Composição envolvendo nanopartículas de prata, quitosana e antibióticos.

\section{QUADRO 2 - Resumo do pedido de patentes UFJF (1995 - 2019)}

\begin{tabular}{|l|c|c|c|c|c|c|}
\hline TIPO & $\begin{array}{c}\text { Patente } \\
\text { de } \\
\text { Invenção } \\
\text { PI }\end{array}$ & $\begin{array}{c}\text { Patente } \\
\text { De } \\
\text { Invenção } \\
\text { Concedida } \\
\text { s }\end{array}$ & $\begin{array}{c}\text { Modelo } \\
\text { de } \\
\text { Utilidad } \\
\text { e MU }\end{array}$ & $\begin{array}{c}\text { Pedido de } \\
\text { Registro de } \\
\text { Software }\end{array}$ & $\begin{array}{c}\text { Pedido de } \\
\text { Registro de } \\
\text { Marcas }\end{array}$ & $\begin{array}{c}\text { Desenho } \\
\text { Industrial }\end{array}$ \\
\hline Total & 118 & 03 & 12 & 21 & 49 & 04 \\
\hline
\end{tabular}

\section{FONTE: CRITT/UFJF}

Conforme dados do IPEA de 2018 sobre os indicadores de propriedade intelectual no Brasil, Minas Gerais se encontra em terceiro lugar entre os estados brasileiros que depositam mais patentes de invenção (participação de 11,6\%). 
GRAFICO 1 - Evolução do número de patentes depositadas

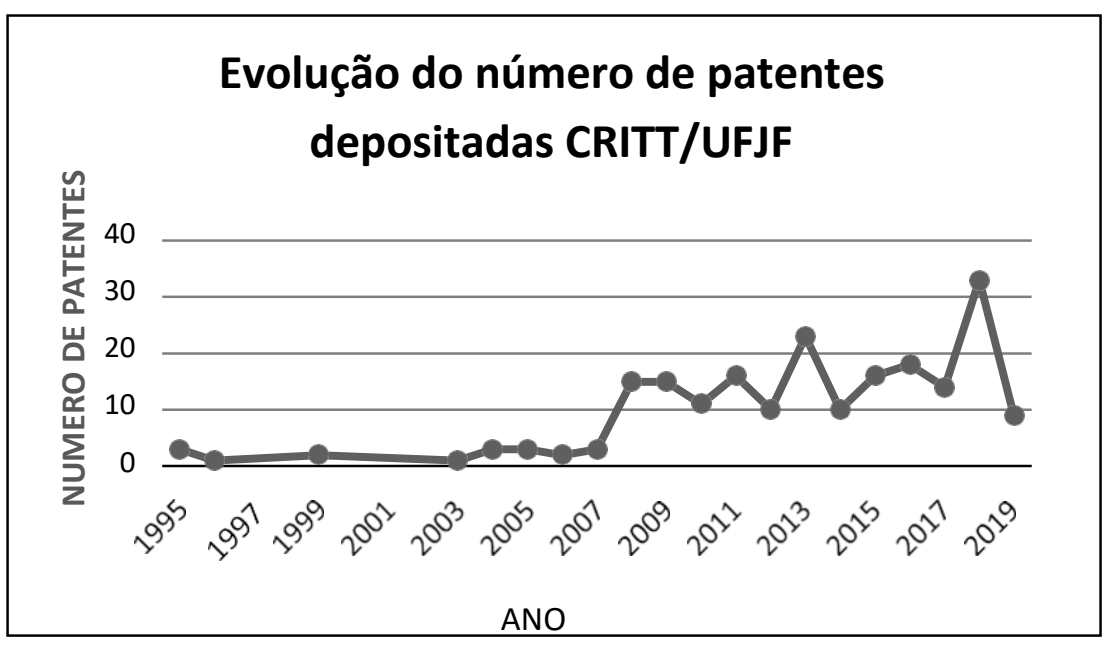

Fonte: elaborado pelos autores

Embora a cidade de Juiz de Fora não esteja entre as dez cidades que mais depositam patentes no Brasil (IPEA, 2018), pode-se verificar que o número de depósitos de patentes por meio do CRITT/UFJF vem crescendo de forma visível. (GRAFICO 1). O incremento no número de patentes pode indicar que os esforços para criar um ambiente inovador e empreendedor estão dando frutos e uma análise dos produtos cujas patentes foram depositadas, indica que parece existir uma preocupação com o bem-estar coletivo e a sustentabilidade socioambiental que envolve as inovações

Especialmente no ano de 2018, foram firmados 24 (vinte e quatro) acordos de parceria com empresas e inventores independentes, totalizando $\mathrm{R} \$ 10.950 .317,84$ (dez milhões, novecentos e cinquenta mil, trezentos e dezessete rais e vinte e quatro centavos) em contratos firmados. (UFJF(b), 2019)

Sob a responsabilidade CRITT o Programa de Incentivo à Inovação - Pii teve duas edições nos anos de 2008 e 2010. A UFJF foi a segunda IFE mineira a participar do Pii e, na primeira edição, atraiu 70 projetos. A primeira fase do Pii ocorreu em 2008 e a segunda em 2010, sendo selecionadas, ao todo, 40 (quarenta) pesquisas aplicadas, em diversas áreas do conhecimento, com possibilidade de se transformarem em produto inovador a ser inserido no mercado ou gerar patentes. Dos 20 selecionados na primeira fase, 13 foram escolhidas para confecção de Planos de Negócios estendido - PNEs, recebendo investimento de 390.000,00 (trezentos e noventa mil reais) para desenvolvimento de protótipos. Na segunda 
edição 71 projetos foram inscritos, sendo 20 selecionados para elaboração de estudo de viabilidade técnica, econômica, comercial e ambiental - EVTECIAS, dos quais 15 foram indicados para prototipagem do produto e confecção de PNEs, com investimento de R\$ 600.000,00 (seiscentos mil reais). (UFJF, 2010)

Ressalta-se que alguns desses projetos receberam prêmios nacionais e internacionais e duas novas empresas de base tecnológica foram implantadas, sendo uma delas incubada na IBT/CRITT.

Em 2017 foi lançado na mesma direção, o INTEC, com 15 (quinze) projetos escritos e 3 selecionados.

Importante observar, que os projetos escolhidos são inovadores, tratam de tecnologias limpas e que buscam redução de custos e preço, de forma a tornar sua aquisição mais acessível, em especial os que se inserem nas áreas de saúde.

\section{- Treinamento}

A capacitação é mais uma forma de promover a Transferência de Tecnologia e criação de uma cultura de inovação e de comportamento empreendedor. Conforme explica o Diretor do CRITT, Ignacio Delgado, as iniciativas de capacitação "perderam intensidade nos últimos anos, em face da restrição existente à cobrança de taxas aos clientes para os quais eram dirigidas, impedindo o recrutamento de pesquisadores da Universidade e outros colaboradores, para ministrar as atividades de treinamento". No entanto, algumas ações foram realizadas como a Semana Qualifique-se que promove durante cinco dias ações de capacitação diversas como workshops, palestras e cursos, envolvendo diversos conteúdos, de forma gratuita, destinados à toda comunidade interna e externa à UFJF. Além disso, há uma constante capacitação dos colaboradores do CRITT, incluindo, estudantes bolsistas e servidores. (UFJF, (b), 2019)

Atualmente, pretende-se aumentar o escopo de atuação o Núcleo de Treinamento de forma a poder desenvolver capacitações para empresas e empresários, inclusive “in job”, além de incrementar as consultorias tecnológicas.

Pode-se citar outras iniciativas como o Programa de Desafios de Inovação que envolve os projetos (Intec), a Bolsa de Apoio à Inovação e à Tecnologia (BiTec) e o projeto Desafios e Hackathons. As bolsas têm o objetivo de incentivar os estudantes a empreenderem por meio de resultados que possam gerar novos negócios ou produtos inovadores, já os Desafios 
e Hackathons, envolvem os estudantes na resolução de problemas propostos pela UFJF ou parceiros.

Neste sentido, foram realizados o Desafio Biomassa (destinado à busca de soluções para uso dos resíduos orgânicos produzidos na Universidade) e o Desafio de Grafite (para estimular a criatividade dos estudantes com um projeto para a fachada do prédio do CRITT); além do Hackathon - JF Inteligente (pela busca de soluções a problemas propostos pela Prefeitura de Juiz de Fora) (UFJF (b), 2019).

\section{Conclusão}

O CRITT/UFJF vem cumprindo seu papel de órgão destinado a promover a inovação e a transferência de conhecimento, porém, novas fronteiras foram alcançadas, até mesmo como frutos de suas realizações ao longo dos anos. Assim como a noção de desenvolvimento ganhou novos contornos evoluindo para uma ideia que busca a sustentabilidade socioambiental e econômica de um território, também as atividades realizadas pelo CRITT vem ganhando novos rumos. Cresceu a preocupação com a formação de uma cultura empreendedora local e com as implicações das atividades realizadas pelo centro para o desenvolvimento sustentável local/regional. Atualmente, há um projeto de disponibilizar um serviço de coworking utilizando as dependências do Centro e, ainda, o eixo finalístico do Treinamento está sendo recuperado de forma a promover a transferência de tecnologia, também na forma de capacitação e consultorias, utilizando os especialistas oriundos da academia, para empresas da região.

Todos os problemas que envolvem a transferência de tecnologia, elencados nesse artigo, se fazem presentes. Embora a cidade de Juiz de Fora possua muitas instituições de ensino superior, as atividades de pesquisa não condizem com o desejado. Os empresários já estabelecidos não possuem o hábito de recorrer a organismos como o CRITT quando buscam inovar. A própria comunidade acadêmica ainda não utiliza o potencial do Centro em toda sua extensão.

No entanto, pode-se perceber que a ideia de um trabalho conjunto, envolvendo os diferentes atores do processo de desenvolvimento vem sendo transformada em ações, mesmo que ainda com alcance limitado. Muito importante a participação dos governos nesse processo, uma vez que facilita e incentiva as ações de fomento à inovação e empreendedorismo, tão importantes para que o desenvolvimento sustentável ocorra, de fato. A hélice quíntupla 
precisa ser acionada de forma a movimentar o ambiente e torná-lo mais propício para iniciativas que produzam empresas saudáveis e preocupadas com as consequências de suas atividades na manutenção e até melhoria das condições de qualidade de vida do território onde se encontram sediadas.

Organismos como o CRITT precisam ganhar mais atenção, deixando de ser apenas uma ponte universidade-empresa para figurar como uma ferramenta importante no planejamento de um desenvolvimento local/regional sustentável.

\section{Referências}

AGUSTINHO, E. O.;GARCIA, E. N.Inovação, Transferência de Tecnologia e Cooperação. : Direito e Desenvolvimento, João Pessoa, v. 9, n. 1, p. 223-239, jan./jul. 2018

ALVES FILHO, J. Matriz energética brasileira: da crise à grande esperança. Rio de Janeiro: Mauad, 2003

ARANTES, A. P.; SERPA, C. V. O modelo da tríplice hélice como fator de desenvolvimento de Santa Rita do Sapucaí. In: XXII Seminário Nacional de Parques Tecnológicos e Incubadoras de Empresas .ANPROTEC, 2012.

BUARQUE, S. C. Construindo o desenvolvimento local sustentável: metodologia de planejamento. 3. ed. Rio de Janeiro: Garamond, 2006.

CARAYANNIS, E. G.; RAKHMATULLIN, R. The Quadruple/Quintuple Innovation Helixes and Smart Specialisation Strategies for Sustainable and Inclusive Growth in Europe and Beyond. Journal of Knowledge Economic. v. 5, p. 212-239, 2014.

CHESBROUG $\mathrm{H}, \mathrm{H}$. Open innovation: the new imperative for creating and profiting from technology. Boston: Harvard Business School Press, p. 272, 2003.

CLOSS, L. et al. Intervenientes na transferência de tecnologia universidade-empresa: o caso PUCRS. Revista Administração Contemporânea. Versão online, v.16, n.1, p.5978, 2012. Disponível em: http://hdl.handle.net/10923/9979 Acesso em: jul. 2019 CENTRO REGIONAL DE INOVAÇÃO E TRANSFERÊNCIA DE TECNOLOGIA (CRITT) -UFJF (a). Empreendedorismo. Disponível em: https://www.ufjf.br/critt/incubadora-de-empresas/Acesso em: jul. 2019 
CENTRO REGIONAL DE INOVAÇÃO E TRANSFERÊNCIA DE TECNOLOGIA (CRITT) -UFJF(b). Transferência de Tecnologia. Disponível em: https://www.ufjf.br/critt/setores/transferencia-de-tecnologia/ Acesso em: jul. 2019.

DE BRITTO, C. M. Sustainable Community Development: A Brief Introduction to the Multi- Modal Systems Method. Systemic Practice and Action Research, v.24, n.6, p.533-544, 2011. ETZKOWITZ, H.; LEYDESDORFF, L. The Triple HelixUniversity-Industry-Government relations: A laboratory for knowledge based economic development. EASST Review, v. 14, p. 14-19. 1995.

INSTITUTO EDUVALDO LODI (IEL). Manual de transferência de tecnologias ecoeficientes: Projeto de Apoio à Inserção Internacional de Pequenas e Médias Empresas PAIIMPE / Instituto Eduvaldo Lodi, Agência Brasileira de Desenvolvimento Industrial. - Brasília : IEL/NC, 2011. Disponível em: https://old.abdi.com.br/Estudo/VersaoWeb_ecoeficiente.pdf Acesso em: jul. 2019

\section{LABIAK, S.J. Método de Análise dos Fluxos de Conhecimento em Sistemas Regionais} de Inovação. 235 f. tese (Doutorado em Engenharia e Gestão do Conhecimento). Programa de Pós-Graduação em Engenharia e Gestão do Conhecimento, Universidade Federal de Santa Catarina, Florianópolis, 2012.

LOTUFO, R. A. A institucionalização do Núcleo de Inovação Tecnológica e a experiência do Inova UNICAMP. In: SANTOS, M. E. R.; TOLEDO, P. T. M.; LOTUDO, R. A.

Transferência de tecnologia: estratégias para a estruturação e gestão de Núcleo de Inovação Tecnológica. Campinas: Komedi, 2009, p. 41 - 73.

MACEDO, N.M.M.N; CÂNDIDO,G.A. Índice de Desenvolvimento Sustentável Local e suas influências nas políticas públicas: um estudo exploratório do município de Alagoa Grande- PB. Gestão da Produção, v.18, n.3, São Carlos, 2011.

MILANI, C. Teorias do Capital Social e Desenvolvimento Local: lições a partir da experiência de Pintadas (Bahia, Brasil). Salvador: Escola de Administração da UFBA (NPGA/NEPOL/PDGS), 2005.

MINEIRO, A,C; et al . Da Hélice Tríplice a Quíntupla: Uma Revisão Sistemática

E\&G Economia e Gestão, Belo Horizonte, v. 18, n. 51, Set./Dez., 2018.

OCDE; FINEP. Manual de Oslo: diretrizes para coleta e interpretação de dados sobre inovação. 3.ed., 2005. Disponível em: https://www.finep.gov.br/images/apoio-efinanciamento/manualoslo.pdf Acesso em: jul. 2019 
OLIVEIRA, J.G.W. Fatores de Atração e Fixação de Empresas de Software em Juiz de Fora: uma análise sob a ótica do desenvolvimento sustentável.142f. dissertação (Mestrado em Engenharia de Produção).Programa de Pós-Graduação em Engenharia Industrial, Pontifícia Universidade Católica do Rio de Janeiro - PUC-Rio, Rio de Janeiro, 2005. .

PAULISTA, G.; VARVAKIS G.; MONTIBELLER-FILHO, G. Espaço emocional e indicadores de sustentabilidade. Ambiente \& Sociedade. Campinas v. 11, n. 1, p. 185 200 Jan.-jun. 2008.

PEARCE, D. W, Sustainable Development. Futures, v. 20, n. 06, p. 598-605, 1988. PETITINGA, C. S. Desenvolvimento Local. In: ALMEIDA, M. C. F. Mais definiçõoes em trânsito. Salvador: Centro de Estudos Multidisciplinares em Cultura. Disponível em:http://www.cult.ufba.br/maisdefinicoes/DESENVOLVIMENTOLOCAL.pdf.

Acesso em: jul.2019

PIMENTEL, L. O. Direito industrial. As funções do direito de patentes. Porto Alegre : Síntese, 1999 PORTER, M. E. Towards a dynamic theory of strategy. Strategic Management Journal, v. 12, p. 95-117, 1991.

PÓVOA L. M. C.; RAPINI, M. S. Technology transfer from universities and public research institutes to firms in Brazil: what is transferred and how the transfer is carried out. Science and Public Policy, v.37, n.02, 147-159, 2010.

PREFEITURA MUNICIPAL DE JUIZ DE FORA (PMJF) - COMDEMA Disponível em: https://www.pif.mg.gov.br/conselhos/comdema/index.php Acesso em: jul. 2019.

REZENDE, A. S. Transferência de Tecnologia e o Desenvolvimento Econômico: uma análise jurídica no âmbito da construção do Satélite Geoestacionário Brasileiro. Disponível em:https://www.portalintelectual.com.br/transferencia-de-tecnologia-e-odesenvolvimento- $\quad$ economico-uma-analise-juridica-no-ambito-da-construcao-dosatelite-geoestacionario- brasileiro-2/\#_ftn1 Acesso em: jul. 2019.

RODRIGUES, R.C.; CARVALHO, Z.V. O papel da formação e da difusão da cultura da inovação e do empreendedorismo como instrumento para o desenvolvimento da quíntupla hélice.In: XXIII Seminário Nacional de Parques Tecnológicos e Incubadoras de Empresas. Anais [...] Belém - PA, 2014.

ROMAN, V.B.;LOPES,M.T. de P. Importância da Transferência de Tecnologia Realizada nas Universidades Brasileiras para A Alavancagem da Competitividade 
do País no Cenário Econômico Mundial. Iberoamerican Journal of Industrial Engineering, Florianópolis, SC, Brasil, v. 4, n. 1, p. 111-124, 2013.

ROSA, L. ITSM: um caso de sucesso do modelo Tríplice Hélice. Brazilian Journal of Management / Revista de Administração da UFSM, Vol.7, p.55-70, 2014.

SACHS, I. Desenvolvimento: includente, sustentável, sustentado. Rio de Janeiro: Garamond, 2004.

SANTANA, E. E. P. S.; PORTO, G. S. E agora, o que fazer com essa tecnologia? um estudo multicaso sobre as possibilidades de transferência de tecnologia na USP-RP. RAC, Curitiba, v. 13, n. 3, art. 4, p. 410-429, jul-ago., 2009

SANTOS, M. E.; SOLLEIRO, J. L. Relações universidade-empresa no Brasil: diagnóstico e perspectivas. In: J. AUDY E M. MOROSINI (Org.), Inovação e Empreendedorismo na Universidade, EDIPUCRS, Porto Alegre, p. 346-376, 2006.

SHUMPETER, J. A. A teoria do desenvolvimento econômico. São Paulo: Editora Nova Cultural, 1997.

UNIVERSIDADE FEDERAL DE JUIZ DE FORA (UFJF) (a). Programa de Incentivo à Inovação na UFJF 2008. Disponível em: https://www.ufjf.br/critt/institucional/parquetecnologico/programa-de-incentivo-a-inovacao/ Acesso em: jul. 2019

UNIVERSIDADE FEDERAL DE JUIZ DE FORA (UFJF)(b). Números expressivos consolidam inovação na universidade. Disponível em: https://www2.ufjf.br/noticias/2018/12/18/numeros-expressivos-consolidam-processode- inovacao-na-universidade/ Acesso em: jul. 2019

YOON, J.; YANG, J; PARK, H. Quintuple helix structure of Sino-Korean research collaboration in science. Scientometrics. v. 113, p. 61-81, 2017.

WORLD ECONOMIC FORUM. The Global Competitive Report 2017-2018. Disponível em http://www3.weforum.org/docs/GCR20172018/05FullReport/TheGlobalCompetitivenessReport2017\%E2\%80\%932018.pdf Acesso em: jul. 2019 